\title{
Language, Trust and Transformation: \\ Exploring Theatre as a Research Method with Migrant Youth
}

\begin{abstract}
:
This article explores the challenges and benefits of using theatre as a research method. It questions certain claims and assumptions underlying Boal's Theatre of the Oppressed and more recent literature on theatre-based research. In particular, it investigates the notion that theatre enables participants to address issues of oppression and create socio-political change. Based on a case study with migrant youth in South Africa, the article firstly argues that certain challenges specific to working with migrants such as differing language skills and a lack of trust may impede genuine dialogic exchange as envisioned by Boal. Secondly, it shows how these challenges can be overcome by incorporating writing exercises, video recordings and embodied communication. Finally, the article argues that theatre-based research can indeed create individual transformations in the form of increased displays of ownership, confidence and hope. These insights contribute to the growing literature on theatre-based research and will be useful for others using similar approaches.
\end{abstract}

Key words: Theatre-based research, arts-based research, Augusto Boal, migrant youth, social transformation

Funding: This research was supported by the Economic and Social Research Council, the Worldwide University Network and the European Union's EUSA_ID Mobility Programme.

Acknowledgements: I thank the participants of this study for their commitment and trust. 


\section{Introduction}

Should art educate, inform, organise, influence, incite to action, or should it simply be an object of pleasure?

Augusto Boal (1979, p. 2)

Researchers aiming to promote social change and challenge traditional modes of knowledge production increasingly resort to using participatory arts-based approaches. Within these approaches, theatre-based methods are becoming more common, especially in research with population groups considered vulnerable or disadvantaged, such as young people affected by migration, poverty or homelessness (e.g. Enria, 2016; Erel, Reynolds, \& Kaptani, 2017; Marín, 2007). Academic accounts of theatre-based studies tend to emphasise the positive role that this method can play in terms of democratising social research and creating socio-political transformation (e.g. Conrad 2004, 2006; Enria 2016; Erel et al. 2017; Marín 2007; Norris 2000, 2009).

This article builds on these accounts and challenges some of their claims by adding insights into challenges that can occur when using theatre with a diverse group of young migrants. The article is based on a research project that used theatre as a research method. By this I mean that theatre exercises were implemented with the specific aim to generate knowledge about participants' lived experiences, thereby substituting other more commonly used qualitative methods such as interviews. ${ }^{1}$ At the same time, I was also interested in researching the theatre-based method itself. Specifically, the research was conducted with a group of undocumented migrant youth in South Africa and had three main objectives. Firstly, it aimed to elicit an in-depth understanding of participants' lived experiences in South Africa. Secondly, it aimed to explore in how far a theatre-based research method is capable of fulfilling enhanced ethics standards when working with vulnerable population groups. Thirdly, the research aimed to investigate the transformative potential of theatre-based research with migrant youth. Since I have discussed the research outcomes regarding the first two objectives elsewhere (Opfermann forthcoming; Opfermann 2015), this article is concerned specifically with the third objective, that is with the question in how far a theatre-based research method can create political, societal or individual transformation.

My assumption that theatre can produce transformation derived from Augusto Boal's use of theatre as an artistic and socio-political interventionist method and on academic accounts of theatre-based research. A close analysis of the methodological findings in this case study leads me to make two main arguments in this article. Firstly, I argue that certain challenges specific to working with migrant youth such as differing language skills and a lack of trust may impede genuine dialogic exchange as envisioned by Boal. Secondly, I argue that theatre-based research can be adapted and modified methodologically to address these challenges in such ways that it can create educational and affective transformation on an individual level. The insights gained through this research contribute to the growing literature on theatre-based research methods and will be useful for other researchers using similar approaches.

The article consists of five main sections. The first section discusses the epistemology of theatre-based knowledge production and the claim that theatre can create social change. This is followed by a brief summary of the research project and the data analysis. The third

\footnotetext{
${ }^{1}$ For an in-depth analysis of the theatrical performances that participants developed during the project see Opfermann (forthcoming).
} 
section analyses how a lack of trust and common language skills among participants impeded a smooth dialogic exchange and created facilitation challenges. The fourth section shows how I tried to mitigate these challenges by amending existing theatre-based methods in innovative ways. The final section elicits how the project created educational and affective benefits for participants that can be described as individual transformations. The article ends with a conclusion summarising the main findings.

\section{Producing knowledge and creating change through theatre}

In terms of the broader philosophical and epistemological understandings of what constitutes knowledge, theatre and other arts-based research methods stand in stark contrast to traditional Western approaches to research. Relying mainly on reason, rationality and writing, traditional positivist approaches to social research devaluate any embodied knowledge such as physical expressions, emotions and feelings (Neuman 2007, 42). Proponents of arts-based research question and condemn these understandings as one-sided and limited. Above all, they question the existence of one truth and instead believe in the existence of multiple meanings which can be uncovered by listening to viewpoints that may be hidden from a positivist view by being less visible, tangible or countable (Eisner 1981; Fleishman 2009, 2012; Leavy 2009; Mander 2010). In this regard Dwight Conquergood argues:

What gets squeezed out by this epistemic violence is the whole realm of complex, finely nuanced meaning that is embodied, tacit, intoned, gestured, improvised, coexperienced, covert - and all the more deeply meaningful because of its refusal to be spelled out. (Conquergood 2002, 146)

What Conquergood describes as 'epistemic violence' refers to the overlooking or denial of viewpoints and meanings that are more difficult to grasp and leave room for interpretive doubt. This overlooking also points to the fact that knowledge and meaning have traditionally been transmitted and recognized through writing only while alternative forms of representing meaning such as performance or dance have been excluded and undervalued (e.g. Conquergood 2002; Nelson 2006; Schneider 2001).

By recognizing alternative expressive forms and allowing multiple meanings to surface, theatre-based research not only intends to produce new knowledge. It also aims to contribute to greater social justice by raising the consciousness of participating individuals and triggering a transformation in the broader society that liberates the oppressed, underprivileged and marginalized (e.g. Denzin 2000; Finley 2003; Leavy 2009; Prentki and Preston 2009). This idea is probably taken furthest in Norman K. Denzin's vision of a 'radical ethical aesthetic' in which he pictures

[a] new generation of scholars [that] is committed not just to describing the world but also to changing it. Their texts are performance based. They inscribe and perform utopian dreams, [...] dreams of a world in which all are free to be who they choose to be, free of gender, class, race, religious, or ethnic prejudice or discrimination. (Denzin 2000, p. 261)

In this endeavour, many practitioners and researchers draw on the philosophies and techniques of Brazilian theatre practitioner Augusto Boal. His work is derived from Paolo Freire's 'Pedagogy of the Oppressed' that proclaims a 'liberating education' in which students do not learn through information transfer, but by developing a consciousness that enables them to reflect critically (Freire 1970). Freire's Pedagogy of the Oppressed is based on the concept of 'dialogical teaching' which aims to establish "a genuine dialogue between student 
and teacher in which both parties undertake the roles of both learner and teacher" (Prentki and Preston 2009, p. 13). For Freire, genuine dialogue depends on a number of preconditions. These include love for the world and its people, humility and acceptance of the other, faith in humankind, hope for a better future and critical thinking (Freire, 1970/2000, p. 91f). According to Freire, "dialogue becomes a horizontal relationship of which mutual trust between the dialoguers is the logical consequence" (Freire 1970/2000, p. 91). In other words, trust will be established automatically through dialogue.

Based on Freire's educational theory and influenced by Bertolt Brecht, Boal developed a revolutionary theatrical practice that he named Theatre of the Oppressed (Boal 1979). Similar to the Pedagogy of the Oppressed, Theatre of the Oppressed relies on dialogic exchange as a tool to create awareness around issues related to social injustice and oppression (Boal 1979; Freire 1970). 'Dialogue' is hereby understood as an interaction between spectators/audience and actors. More specifically, Boal deliberately blurred the lines between actors and audience in order to transform spectators from passive beings into active participants that form part of the dramatic action. To stimulate this exchange, actors perform short improvised scenes in which an oppressed person fails to deal with their situation. This failure is intended to spur the audience "into finding solutions and inventing new ways of confronting oppression" (Boal 2002, p. 242). After watching this 'anti-model', audience members are therefore invited to modify the scene by suggesting changes to the protagonist's behaviour. The same scene will then be re-enacted and changed several times with the aim to turn it into the 'model' in which the protagonist is able to overcome their oppression. The repeated re-enactment of the same scene is said to make the spectators conscious of oppressive circumstances in their real lives as well as of their own potential to change these circumstances. This process of 'conscientização' ('conscientization') is considered to be a 'liberation of the self'.

Boal saw participants' engagement in constructing a play as a 'rehearsal for revolution' that sparks courage and motivation to perform the same actions in real life. According to him, "The practice of these theatrical forms creates a sort of uneasy sense of incompleteness that seeks fulfilment through real action." (Boal 1979, p. 142) Theatre of the Oppressed is thus said to cause a double effect. Firstly, it 'liberates' actors and spectators individually by creating a consciousness regarding the oppression they experience and their own capacities in overcoming this condition. Secondly, participants' increased consciousness leads to action that will trigger a transformation in society as a whole.

Despite its continued popularity, critiques have argued that Theatre of the Oppressed practices are unsuitable for dealing with the increasingly complex political and social conditions faced by many marginalized people today (Snyder-Young 2011). Related to this, Boal's 'revolutionary' terminology has been criticised for being too violent: "It is very hard to be creating a theatre for peace, when the language of this form of community theatre is strewn with words that imply violent resistance - struggle, fight, oppressed, liberate, resist" (Thompson 2002, 112). The concern, therefore, is that Boal's approach may reinforce rather than change people's existing attitudes. Similarly, others have observed that "[t]he work participants initiate and the choices they make do not automatically orient towards social justice" (Snyder-Young 2011, p. 30). This may be the case when participants voice sexist, racist or otherwise discriminatory views contrary to those which the facilitator envisions as liberating (Conrad 2006). As these concerns indicate and the analysis in this article will demonstrate further, reaching transformation may not necessarily occur as straight forwardly as assumed. 


\section{Summary of the research project}

The research on which this article is based took place in 2014 over a four-month period and comprised 29 workshops. The core group of participants were ten undocumented migrant youth aged 13 to 21 of Angolan, Congolese, Rwandan and Zimbabwean nationalities who did not know each other before the project. ${ }^{2}$ As mentioned above, the research aimed to explore participants' experiences in South Africa and the usefulness of theatre as a research method in terms of research ethics and in terms of achieving socio-political transformation. In order to explore these questions, we implemented a range of theatre-based activities such as mime, role play, improvisation but also creative writing and drawing exercises. The project ended with a final performance for a selected public audience in which participants showcased some of the scenes they had developed during the project. The performance was created on the basis of participants' own initiative and was not initially planned as a fixed component or outcome of the research. The analysis in this article therefore refers mainly to the workshop phase though references to the final performance are made particularly in section five of the article where I illustrate that the final performance became significant with regard to the overall meaning of the project for participants and their transformations.

In terms of my positionality I was highly conscious that differences in age, race, national origin, legal status, educational and socio-economic background created various layers of power imbalances between myself and the participants. This awareness and my desire to ensure that all participants benefitted directly from taking part in this project had influenced my decision to use theatre as a research method. The project was therefore guided by the assumption that theatre is capable of creating both in-depth meanings and of fostering social change.

Due to the variety of techniques implemented during the project the data consisted of different forms including ethnographic notes, photographs and video recordings of acting exercises, scene rehearsals, performances and group conversations. It also included written materials produced by participants such as postcards, letters, diaries and posters, drawings and confidential video recordings from individual participants. ${ }^{3}$ After the project I inserted all the written and transcribed data into a table and conducted a manual two-cycle coding process. Coding can be defined as "the transitional process between data collection and more extensive data analysis" (Saldaña 2009, p. 4). It "encourages higher-level thinking about the data and moves a researcher toward theoretical generalizations" (Neuman 2007, p. 330). ${ }^{4}$ The analysis of the methodological challenges in the following section is based on the results of this coding exercise in which 'trust' and 'language' were recurring themes.

\footnotetext{
2 Participants were recruited with the help of a local NGO. Prior to the research I had obtained formal ethics approval from the University of York as well as written informed consent from caregivers and participants. Throughout the project I maintained contact with the caregivers and regularly emphasised that participants were free to opt out of any activities.

${ }^{3}$ In arts-based research it is common to start analysing the data during the data collection process (Dennis 2009; Neuman 2007). In accordance with this, I undertook a preliminary analysis during the workshop phase which served to verify my understanding of participants' views and was intended to find answers to the first research question. The in-depth analysis of data concerning the third, methodological, research question discussed in this article took place after the project.

${ }^{4}$ In reviewing the data I allowed the codes to emerge spontaneously. However, this process was also guided by my research questions. I used different colours to differentiate between reflective codes (red); factual codes (black); those referring to methodological issues (blue); and codes that referred to acting such as monologues and dialogues (green).
} 


\section{Methodological Challenges: Trust and Language}

As described above, dialogic exchange, as the assumed basis for transformation, relies on participants sharing stories about their experiences of struggle or oppression. This storytelling in the group is often described as a natural process in which 'stories beget stories as one idea triggers forgotten stories by other cast members' (Norris 2000, p. 46). In this project, however, stories were not shared in the group as easily as described here. I will illustrate in this section that participants' hesitation to share personal stories was due to a lack of trust towards each other as well as due to a lack of shared language skills. These methodological impediments in turn resulted in facilitation challenges concerning participants' discipline and respect.

\section{Trust}

Based on Boal's writings and other literature on theatre-based research I had assumed that sharing a particular struggle or sense of oppression, in this case an undocumented legal status in a foreign country, would create a basis of trust among participants which would make them feel at ease to share personal experiences with the group. However, it became clear that this commonality was not enough for participants to trust each other. In order to allow any kind of interaction and exchange to take place, we therefore had to consciously work towards establishing a level of trust within the group. One way to do this was through the 'trust circle' exercise in which participants stand in a narrow circle surrounding one person in the middle. With closed eyes the person in the middle has to let themselves fall in any direction and be caught by the surrounding participants. Initially, hardly anyone felt comfortable in the middle as they did not trust the others to catch them. Some participants also did not trust themselves to be able to catch the person in the middle. As we repeated the exercise over the weeks, more participants volunteered to stand in the middle, indicating an increased level of trust towards the others.

This development occurred alongside participants becoming friends, spending time with each other even outside the workshop times and expressing concern if anyone arrived late or not at all. Some participants also began using the project as a space to receive support, mentioning for example in group conversations that they were struggling at school. One participant openly shared the news about her cousin's recent death and told the group how she had been assaulted on her way home from church.

In spite of and in contrast to the caring attitude and friendships that developed between participants, an element of distrust towards each other remained. This was demonstrated by several participants' continued refusal to be in the middle of the trust circle as well as by their persistent caution with regard to sharing personal information and opinions with the group. It is not a new phenomenon that migrants remain silent, especially when interacting with state authorities, psychologists, social workers and researchers (Chase 2009; Ghorashi 2008; Kohli 2006). With regard to unaccompanied asylum-seeking children in the United Kingdom, Elaine Chase argues that children's 'selective disclosure' derives from "a desire to retain a degree of agency" in the face of constant scrutiny and surveillance by immigration officials, social workers and other actors (Chase 2009, p. 3). In such contexts, silence can be an expression of functional distrust, used as a means of maintaining integrity "in a potentially hostile encounter" (Kohli 2006, p. 712).

The overlap between silence and functional distrust as a precautionary measure became apparent in the reactions to a participant's statement that he had come to South Africa 'for school'. Apparently alerted by this comment, another participant subsequently 
asked: "This stuff we talk here, you gonna go and tell South Africans?" This reaction indicated that he perceived the other participant's comment as inappropriate. His discomfort indicates that he may have been advised that education is not necessarily considered a legitimate reason to come to South Africa. Above all, however, his reaction shows that he was not completely sure how much he could trust the facilitator or the other group members. The incident illustrated that there were issues participants preferred to keep to themselves for reasons of 'functional distrust'.

In order to avoid triggering sad or traumatic memories from participants' past, the workshops focused on exploring current everyday experiences. However, while Kohli refers to refugees remaining silent concerning their past, participants in this project also hesitated to share personal thoughts and information about their present lives including their family situation, living arrangements and school attendance. Overall, we can therefore say that a lack of trust inhibited an open exchange of personal opinions that could have stimulated debate about participants' lived experiences as undocumented youth in South Africa. In addition, the lack of a shared spoken language in the group was equally significant.

\section{Language skills}

Since English was neither mine nor most participants' first language, I had chosen theatre partly due to the assumption that its embodied communication substitutes the need for spoken language. In contrast to this assumption, however, verbal communication is in fact a crucial component of both Theatre of the Oppressed (TO) and theatre-based research more specifically. Verbal communication occurs for instance when facilitators give instructions, when participants devise scenes, when actors speak on stage and when audience members provide feedback. The role and indeed the need of having a shared oral language, however, hardly features in the literature. One exception is an article about a TO project with school children which highlights that "verbal improvisation ability (i.e. oral language skills) of older children" resulted in a better success of the project among fifth graders than fourth graders (Saldaña 2005, 127).

In this project, several participants were unable to fully understand English and some felt uncomfortable in expressing themselves in English. This lack of a common language created a number of challenges. Firstly, we did not have a formal translator and therefore relied on participants to translate for each other as well as on my own limited French skills. Participants who spoke both English and Lingala were often hesitant to translate, either because their English skills were also limited or because they did not want to be seen as speaking Lingala. ${ }^{5}$ This situation made constant translating of instructions, group discussions and reflective conversations unfeasible and inhibited the transmission of more complex questions or instructions. Secondly, the inequality in terms of language skills created a situation in which some participants with more proficient English skills were keen on serious discussions whereas others showed no particular interest and regularly disrupted group activities. These disruptions created additional challenges in terms of facilitation and in terms of the overall research process.

According to Boal, games and dialogue must be governed by discipline and clear rules (Boal, 1979, 2002, p. 270). However, I felt that setting up rules would have reinforced my position of power and therefore adopted a facilitation approach that maintained a relatively flat hierarchy. This approach implied, for instance, that participants were free to comply with

\footnotetext{
${ }^{5}$ Despite being one of the dominant languages spoken in the Democratic Republic of Congo, some participants considered it as a rural language and felt embarrassed to speak it in front of others.
} 
my constructions or to disobey them and that they were not 'punished' if they did not comply. Since disruptions were common in the first two sessions, I asked participants to create a set of rules for the workshops. Despite the rules, however, many participants often had side conversations while someone else was talking, they made jokes or rude comments about others, interrupted others by commenting, laughing or giggling, spontaneously retreated from group conversations or refused to participate in activities.

As a researcher, I was concerned that these behaviour patterns impeded the group from working in a way that I felt was necessary in order to achieve the research results I was aiming for. In other words, I feared that the disruptions and disrespect by certain group members prevented some participants from expressing their thoughts. My project diary reflects how the workshops often left me feeling drained, frustrated and concerned about the development of the project.

In addition to the challenging group dynamics, I think that my sense of frustration is linked to the pressure of being successful, finding responses to my research questions about the children's experiences etc. and of getting the group to a stage in which they openly discuss and reflect on their experiences. I realized that my list of questions may be too ambitious, certainly in the time frame of three months. (author's notes, 17 July 2014)

Similarly, those participants who enjoyed engaging in serious conversations and were keen on participating in the exercises became increasingly frustrated by the others' lack of respect. This situation led me to consider whether it would be beneficial for the group to exclude certain particularly disruptive participants. The following excerpt from my project diary speaks to this dilemma:

It is a very tricky situation and I don't know how to handle it yet. Would it be ethical to exclude them? Is it on the other hand ethical to let them impact the project negatively and contribute to the silence of other children who would otherwise like to share more personal thoughts with the group? (author's notes, 13 August 2014)

I finally decided that it would be both unethical towards individuals and damaging for the group to exclude participants. With a second set of self-set rules and the final performance approaching, the general levels of respect and participation eventually increased, though challenging behaviour patterns continued occurring until the end.

In hindsight, I suggest that some participants' disruptive behaviour may have been a strategy to avoid engaging in conversations or being questioned themselves. If this was the case, disrespect and disobedience can be interpreted not only as a consequence of their limited English skills but also as a symptom of their functional distrust towards the group. Besides this, it is also possible that participants simply enjoyed the liberty of behaving freely without being reprimanded, especially since their lives were otherwise highly restricted due to their precarious legal status. As I will show in the final section of the article, participants' feedback at the end of the project showed that overcoming these disciplinary struggles as a group created an enormous sense of achievement and pride.

This brief analysis showed how a lack of trust and common language prevented open discussions about experiences of oppression in the group and impeded dialogic exchange as envisioned by Boal. Nevertheless, the following section shows how we managed to mitigate these challenges to a certain extent by introducing a new set of techniques. 


\section{Finding Solutions: Writing exercises, Video Recording and Embodied}

\section{Communication}

It is important to keep in mind that Theatre of the Oppressed (TO) was originally created as a method of socio-political intervention and not as a research method. From the outset, I therefore had not intended to apply TO in its original design but rather to draw on the TO repertoire of exercises (Boal 2002) and adapt them to suit this particular group. This is nothing novel in itself as TO techniques have been adapted to serve many other purposes, including research (e.g. Conrad 2004, Dennis 2009, Norris 2008; Kaptani and Yuval Davis 2008, Erel et al. 2017). However, the particular set of challenges faced in this project have rarely been discussed elsewhere. As other researchers using theatre with migrants are likely to face similar challenges, I will now outline the solutions I came up with in this project. In this regard it proved to be helpful to move away from verbal communication with the whole group and to focus on individual writing exercises, video recordings and embodied practice. I will briefly outline each of these three solutions.

\section{Writing exercises}

As mentioned before, a number of games in which participants had to physically relate to, support and depend on each other were useful to both foster and measure the level of trust in the group. It was clear, however, that despite increasing levels of trust participants continued feeling shy or uncomfortable in sharing personal information with the group. I therefore looked for more confidential ways of communicating and found writing exercises to be a useful solution in this regard.

The most common writing activity were individual 'postcards'. For this purpose, each participant received a postcard-size card and pen. Participants were then asked to respond to a particular question in writing. Basic instructions about contrasting issues such as describing 'a good and a bad experience' or 'a happy and a sad memory' generally worked well. Responses could be written in English or French and I offered help to anyone who requested it. The postcards had the purpose of allowing participants to share personal information with me without having to share it with the other members of the group. I emphasised that they were free to write anything, that there were no right or wrong answers and that spelling mistakes were irrelevant. Upon completion, they put their cards into a 'post box' . I explained that, comparable to normal post, any written material they put inside that box would be kept confidential and would only be seen by myself.

I also distributed 'diaries' as a further opportunity to share thoughts in writing. The idea was that participants would do a weekly written 'homework' that would allow them to reflect on issues that had come up in the workshops, to develop some further thoughts or respond to particular questions. Initially, participants responded positively. However, the diaries soon lost momentum and participants became unreliable in completing their tasks, some lost their diaries or left them at home. At the end of the project only two participants returned their diaries to me. I consider this to be a missed opportunity and a loss of relevant data. In retrospect, however, I acknowledge that part of the reason for this failure was my own uncertainty concerning the use and purpose of the diaries, which prevented me from giving clear instructions. This uncertainty derived from an ethical concern. Unlike postcards, which can be directed to someone and are usually written with the intention of sharing its content with someone else, diaries are by definition very personal objects. I therefore did not 
feel comfortable insisting on participants sharing their homework with the group or returning their diaries to me.

\section{Confidential video recordings}

Besides writing, video recordings proved to be another useful technique to tackle both trust and language difficulties. While writing exercises provided an opportunity for individualised and confidential communication, some participants felt more comfortable communicating orally. In response to this, the idea came up to record individual messages on video in a separate room without anyone else present. As the recordings would not be shared with the group, we could say the technique essentially represented a digital version of the postcard exercise. We used this technique on two principal occasions. In one instance, a participant was hesitant to complete the task of writing down a dream. As an alternative, he was thus given the opportunity to record his dream on video. The result was a strikingly personal account in which he spoke of his deceased parents and that he misses them a lot, that he feels lonely and dreams of having a good girlfriend with whom to have a family. The participant later on decided to include his wish to have a big family in the opening scene of the final performance in which all participants made a one-line statement about a dream for their future. Considering that he had previously never spoken about his personal thoughts and feelings in front of the group, sharing this dream in public was significant and may not have happened had he not shared the dream on camera beforehand.

The second occasion to use video took place at the end of the project. In order to evaluate participants' impressions of the project, I asked them to record individual video messages in a separate room. As a trigger, I gave them cards with the statements 'what I liked about the project', 'what I did not like about the project' and 'anything else I want to say'. I will discuss some of the outcomes of these evaluations in the final section of the article.

On both occasions, video was chosen to provide participants an opportunity to express personal stories or messages in a confidential way. As the two examples have shown, the technique proved to be highly successful in this regard. The first participant, for instance, 'trusted' the camera enough to share a highly sensitive personal message that he had on his mind but that he did not feel comfortable writing down or telling the group. This indicates that a video camera can at times function as a mediating tool that takes away the immediacy of a personal conversation while nevertheless allowing for direct and confidential communication. The fact that the young people were alone with the camera meant there was nobody there to judge either their language skills or the content of their messages, thus creating a 'safe' space to communicating freely.

Despite the usefulness of the writing exercises and video recordings, however, we still needed to find ways to communicate effectively in the group. The following section will illustrate that embodied communication through still images, improvisation and role play proved to work well in this regard.

\section{Embodied communication}

In order to familiarize participants with the feeling of physically being on stage, we used a number of different techniques, again partly drawing on Boal's techniques and other existing repertoires (e.g. Boal 2002). One common technique is that of still images. A still image can be portrayed as an individual or as a group portrait and can represent a situation, an action or an emotion. It was a useful exercise that encouraged participants to be on stage without the need to physically move or use their voice. Similarly, we also used mime as a technique to 
show emotions and actions on stage without the need for speech. Other key techniques were characterisations \& role-plays. We practised those by asking participants to portray characters that appeared in a story told by the facilitator. Due to the language issues, stories had to be told in simple and easily understandable words.

In some instances, we merely described a context in which a certain situation would take place. For example, we asked participants to imagine the area of Cape Town they currently live in. One participant was then asked to portray a local South African residing in this area while a second participant would adopt the role of a foreign person who arrives in this area for the first time. Both characters then acted out an encounter between the two.

At a later stage we moved to improvising scenes based on real occurrences or experiences. Since the portrayal of real occurrences was more sensitive than portraying imagined scenes, we used a multi-stage approach in order to ensure that participants only exposed and represented what they felt comfortable to share. As a first step participants were again asked to respond to a question or a statement individually in writing. In the second step, they compared their responses in small groups of two or three. They then decided which aspects they agreed on and wanted to act out in an improvised way to the rest of the group. For instance, participants were asked to comment on the statement 'I miss my family'. In the small group discussion, one participant told the others that he indeed missed his family a lot. The other group members shared his sentiment and the group subsequently decided to develop a scene in which a boy wakes up at night crying for his mother (see author 2019 for an analysis of the content of these scenes).

Most scenes involved only short dialogues or monologues. In order to mitigate the hurdle of using English on stage we also encouraged participants to speak in any language they wanted to. We also introduced Gibberish as an invented language that can be spoken by anyone by making up words and sounds at the moment of speaking. While Gibberish can be a useful tool, it took some practice until participants felt comfortable in using it. Because of the lack of spoken language, many of the performed scenes relied on physical movement. It was here that the purpose of using theatre as a research method became most obvious as the bodily movements, mimes and gestures transmitted nuances of experiences of loneliness, pain and discrimination that words alone may not have been able to describe.

After performing the improvised scenes, the rest of the group were asked to comment on what they had seen. Participants were generally keen to provide feedback, yet language skills and trust limited the depth of these discussions. I could conclude from this absence of meaningful dialogic exchange that it was not possible to achieve any transformation. The following section will show, however, that the project did create certain transformations.

\section{Individual Transformations: Ownership and Laughter}

This article aimed to address the question in how far theatre-based research with a diverse group of migrant youth is capable of achieving transformation. Boal spoke of individual transformation in the sense of increasing people's awareness concerning the oppression they experience in their daily lives (Boal 1979). In this research, it became clear that participants were already highly aware of the oppression they experience as undocumented migrants in a society that is extremely hostile towards African foreigners. It was also clear that it would not be possible to significantly change these circumstances as this would have required changing the legislative framework as well as societal attitudes. Nevertheless, the project resulted in certain observable changes that I argue can be considered individual transformations. 


\section{Ownership and Agency}

Having emphasised that language was a major obstacle, one noticeable transformation actually took place with regard to participants' English skills which significantly improved over the course of the project. This was particularly evident in the case of participants who initially struggled to understand or express themselves in English but were able to hold fluent conversations later on. Perhaps linked to this, participants' confidence when expressing themselves both orally and physically through acting and roleplaying also increased in the course of the project, as can be seen by comparing video recordings from earlier workshops to later ones. One participant explicitly recognized in her final evaluation that the theatrebased activities increased her self-confidence:

What I also liked about the project was [...] I'm a very shy person, so basically I built a little bit of confidence, you know, when we were acting on stage, because usually I just do poetry, but like silent poetry, I just write, I don't say it on stage and I think this helped me a lot. [...] improvising, being able to speak loud enough so that people can hear you.

Her statement also shows that the different activities allowed participants to acquire certain skills such as speaking in front of an audience, miming and improvising. Perhaps more importantly, however, was the acquisition of social competences that enabled participants to express their opinion, work in a team and manage conflicts in the group. These developments are noticeable in participants' reflections on the disciplinary issues discussed earlier and on how they have overcome these challenges as a group.

When we started off [...], some people would be talking when they were not spoken to [...]. We lacked respect as a group, you know, we lacked discipline at the same time as well. But that's not the point because at the end we became tighter and we felt comfortable around each other and the discipline, everything was on point, even though it was not on on [sic] point, but like, we were focused.

Participants' statements also reveal a sense of pride for having mastered these challenges:

What I liked about this project was that we reached the end. We reached what we wanted to do, we finished what we wanted to do and we got through the challenge of getting to know each other and all those other things. What I did not like about the project was that some people did not cooperate and some kept misbehaving and [...] some of us thought that we could not get [to] the end of this project, but some people kept their hopes up and at the end people started cooperating and the project became a success.

These and other evaluations show that it was precisely the bumpy road of the group building process and overcoming disciplinary challenges that ultimately resulted in the young people's sense of achievement and ownership. Based on these insights I suggest that a stricter facilitation approach geared towards enforcing discipline may perhaps have reduced the amount of frustration and exhaustion I felt as a facilitator and researcher, but it most likely would not have produced the same results.

Drawing on examples linked to the final performance I will now argue that participants' ownership of the project can be read as further evidence of individual transformations. To begin with, participants chose to entitle the performance 'Innocent Voices'. This title emphasised not only that the performance represented their own voices but also that their voices, and hence the actors as persons, were innocent. The title thus constitutes an expression of agency as it tells the audience that the voices they will hear cannot be blamed 
for the injustice they represent. Secondly, during the final performance all actors chose to present themselves to the audience with their real names instead of maintaining anonymity by using their stage names or their characters' names as previously rehearsed. Thirdly, some actors disobeyed the instructions concerning the performance dress code by appearing on stage with additional pieces of clothing such as sunglasses and caps. Finally, following the performance, all actors agreed to sit on stage and respond to questions from the audience, moderated by one of the actors.

All these assertions of ownership and agency were highly significant. They illustrated that the young people were in charge of the performance and can be credited for the artistic outcome of the project. They also demonstrated the young people's agency in determining how they represent themselves to the public both in terms of their personal identity and appearance. This is particularly relevant in the context of participants' undocumented legal status which usually compels them to hide or to blend in in public in order to avoid being identified and caught by the police. By publicly responding to questions from the audience participants broke out of these everyday restrictions and fears and instead presented themselves as the experts of their own lives and as 'the authority that owned the stage' (see Thompson 2009, 183 on a similar situation).

I argue that participants' development from individuals who are otherwise oppressed and pitied into 'experts' who own the stage and are admired by others constitutes a transformation. This transformation can be accredited to the theatre-based research process through which participants developed the confidence and determination to publicly display their agency and ownership in this way.

\section{Courage and Hope}

While the sense of ownership and pride developed predominantly towards the end of the project, participants enjoyed the workshops throughout. This was because they enjoyed the different exercises but also because they were happy to see their friends whom they started considering as family, as the following statement by a participant illustrates:

Ok, the first time they [the others] were talking and laughing too much and I was like 'agh, I don't like people who laugh too much', but then, you know, I got used to them and wow, we became so close that you could say we are family because it felt as if we were family.

Since participants did not know much about each other's backgrounds, the association and perception of the group as a 'family' is remarkable. While the sense of family may not have translated into a deep trust, it did mean that participants started feeling at ease in the workshops. The following message by another participant represents this feeling:

I liked the fact that I could show off my talent, my acting talent to some people here [...]. And yeah, I liked it a lot coz around them I don't feel shy at all, I just feel myself and it was really nice. [...] I really really enjoyed being in this workshop, I wish it could last longer, I really do, I had fun. (emphasis added)

Participants' feedback at the end and during the workshops also clearly indicates that they enjoyed the project because they had fun. This is illustrated in their repeated referral to laughter in relation to the project. One day, for example, one participant commented in a group conversation: 'Sometimes when I' $m$ at home I think about the workshop and then I just start laughing.' In response to this, several other participants confirmed that they also started laughing at any given time during the week when they thought about the workshops and the 
fun they had there. After the project, one participant said to me that 'now there won't be any more laughter on Sundays'.

Describing communal laughter as a shared experience of 'ultimate self-loss', Joris Vlieghe et al. suggest that in communal laughter "we passively succumb to a corporeal experience that makes any position or identity meaningless" (Vervliet et al. 2015, 734). In other words, "in communal laughter the only thing that matters is that we are flesh" (ibid., p. 729, emphasis in original). This, they argue further, "is an equalizing experience that implies that everything could start anew" (ibid.). The interpretation of laughter as an experience of 'equality' that allows for a new imagination of the future is particularly meaningful in the context of this project. Since participants are exposed to constant oppression and discrimination in their daily lives, the possibility to laugh with others 'as equals' in both a literal and figurative sense is a meaningful experience.

As the association of the project with laughter, joy, friendships and family indicates, the project provided a space where participants felt free and safe and developed a sense of belonging in the absence of their own immediate families. This allowed them to reflect on and process personal experiences even if they kept some of these thoughts to themselves. The case of a participant who, after the project, decided to start a family tracing process in his home country in order to re-establish contact with his family after several years of separation, illustrates this point. Returning to the question of transformation, I argue based on these observations that even without the prospect of finding a solution that would have 'liberated' the young people from the exclusion and discrimination they experience in South Africa, their participation in this theatre-based project had a second transformative effect. This transformation refers to the creation of courage to face previously suppressed personally challenging or sensitive matters such as acknowledging personal loss or looking for lost family members. Even more, I argue that laughter, friendships and performing their own 'hopeless' situation ultimately translated into a form of hope that allowed for the imagination of a different reality and a better future. The participant's act of publicly stating his dream of a big family exemplifies this notion. Similarly, it is reflected in the following meaningful video message by another participant:

\section{What I liked about the project was interacting with foreign kids [...]. Knowing their struggles are my struggles as well and sometimes I think when we are in a situation like this a lot of people don't understand, especially if they don't know about such situations. [...]l hope that we can have another opportunity, maybe some time we can do it across the borders, overseas, and just show them that foreign kids, we have feelings, we understand, some of us were born here, some of us came here, some of us escaped, some of us came here alone, no parents, nothing, but we try our best to make it work for us. And that's all we have, innocent voices. [emphasis added]}

Born in South Africa to foreign parents, this participant is fully aware that changing her legal status is and will remain a challenge. Yet she expresses clearly the many ways in which she benefitted from participating in this project, not necessarily by having her situation change from the outset but simply by 'being there' and by meeting others with similar struggles. This point speaks to the argument that the real transformation in drama takes place through a series of 'affective transactions' like gestures, sounds and relationships rather than by providing solutions and raising consciousness through direct communication (Thompson 2009, 131). 'Affect', as "the bodily sensation that is sustained and provoked particularly by aesthetic experiences [...] is the force that emerges from attention to pleasure, astonishment, joy, and beauty" (ibid., p. 132). It can be triggered by watching a performance, observing a 
situation or recalling a memory. In this case, it was the participation in a theatre-based research project that allowed all those transactions to take place and to 'transform' participants in a positive way.

\section{Conclusion}

This article showed that using theatre as a research method poses certain challenges, especially when applied with diverse groups of migrant youth. While existing literature emphasises that storytelling in the group occurs naturally and creates socio-political transformation (e.g. Dennis 2009; Marín 2007; Norris 2009), the importance of verbal communication and trust are hardly reflected on in these accounts. I suggest that this omission derives from the fact that most projects referred to in the literature were implemented in school contexts or with existing youth or drama groups that already had a certain level of trust, discipline and a common language of communication established. This article showed how a lack of these preconditions can impede both story-telling and effective dialogic exchange.

Yet the article also demonstrated how modifying existing techniques created spaces and opportunities in which participants felt comfortable to share personal thoughts and feelings through writing, video recording and acting. The process of reflecting on and discussing topics related to participants' everyday lives allowed embodied and sometimes suppressed knowledge such as a longing for their absent families to surface. I argued that this surfacing of previously hidden sentiments and the courage to confront these through performative display on stage or real-life actions is a sign of transformation on an individual level.

Boal saw theatre-making in the group as a 'rehearsal for revolution' that sparks courage and motivation to perform the same actions in real life (Boal 1979, p.141). While not geared towards revolution or even any form of political action, participants' confident display of ownership and agency towards the end of this project similarly illustrated that they have gained courage and motivation to confront and denounce their everyday challenges and oppression. Based on these insights I have argued that this project created transformation through affective transactions which took place through theatre-based activities such as role play but also shared laughter and friendships. I also suggested that these transactions allowed participants to develop hope for a better future, even without the prospect of changing their current situation of oppression as undocumented migrants. This point relates to a statement by Freire in which he proposes that "in order for the oppressed to be able to wage the struggle for their liberation, they must perceive the reality of oppression not as a closed world from which there is no exit, but as a limiting situation which they can transform" (Freire 1970, p. 49, emphasis added). Participants' open display of ownership and agency, their increased confidence, courage and hope can be interpreted as such a transformation of their 'limiting situation'.

With a view on the meaning of fun and laughter in this project I close this account by suggesting in reference to Boal's opening quote that it is perhaps precisely by 'simply being an object of pleasure' that arts-based research does in fact educate, inform, influence and incite to action. Researchers with ambitions to democratise knowledge production and produce social change might keep this in mind. 


\section{Bibliography}

Boal, Augusto. 1979/2000. Theatre of the Oppressed. London: Pluto Press.

- - . 2002. Games for Actors and Non-Actors. 2nd ed. London: Routledge.

Chase, Elaine. 2009. 'Agency and Silence: Young People Seeking Asylum Alone in the UK'. British Journal of Social Work 40 (7): 2050-2068.

Conquergood, Dwight. 2002. 'Performance Studies: Interventions and Radical Research'. TDR/The Drama Review 46 (2): 145-56.

Conrad, Diane. 2004. 'Exploring Risky Youth Experiences: Popular Theatre as a Participatory, Performative Research Method'. International Journal of Qualitative Methods 3 (1): 12-24.

---. 2006. 'Entangled (in the) Sticks: Ethical Conundrums of Popular Theater as Pedagogy and Research'. Qualitative Inquiry 12 (3): 437-58.

Dennis, Barbara Kathleen. 2009. 'Acting Up: Theater of the Oppressed as Critical Ethnography'. International Journal of Qualitative Methods 8 (2): 65-96.

Denzin, Norman K. 2000. 'Aesthetics and the Practices of Qualitative Inquiry'. Qualitative Inquiry 6 (2): 256-65.

Eisner, Elliot W. 1981. 'On the Differences between Scientific and Artistic Approaches to Qualitative Research'. Educational Researcher 10 (4): 5-9.

Enria, Luisa. 2016. 'Co-Producing Knowledge through Participatory Theatre: Reflections on Ethnography, Empathy and Power'. Qualitative Research 16 (3): 319-29.

Erel, Umut, Tracey Reynolds, and Erene Kaptani. 2017. 'Participatory Theatre for Transformative Social Research'. Qualitative Research 17 (3): 302-12.

Finley, Susan. 2003. 'Arts-Based Inquiry in QI: Seven Years From Crisis to Guerrilla Warfare'. Qualitative Inquiry 9 (2): 281-96.

Fleishman, Mark. 2009. 'Knowing Performance: Performance as Knowledge Paradigm for Africa'. SATJ: South African Theatre Journal 23: 116-136.

- - . 2012. 'The Difference of Performance as Research'. Theatre Research International 37 (01): 28-37.

Freire, Paulo. 1970. Pedagogy of the Oppressed. 30th anniversary ed. New York: Continuum.

Ghorashi, Halleh. 2008. 'Giving Silence a Chance: The Importance of Life Stories for Research on Refugees'. Journal of Refugee Studies 21: 117.

Kohli, Ravi K. S. 2006. 'The Sound Of Silence: Listening to What Unaccompanied AsylumSeeking Children Say and Do Not Say'. British Journal of Social Work 36 (5): 707-21.

Leavy, Patricia. 2009. Method Meets Art: Arts-Based Research Practice. New York; London: Guilford Press.

Mander, Harsh. 2010. "'Words from the Heart": Researching People's Stories'. Journal of Human Rights Practice 2 (2): 252-70.

Marín, Christina. 2007. 'A Methodology Rooted in Praxis: Theatre of the Oppressed (TO) Techniques Employed as Arts-Based Educational Research Methods'. Youth Theatre Journal 21 (1): 81-93.

Nelson, Robin. 2006. 'Practice-as-Research and the Problem of Knowledge'. Performance Research 11 (4): 105-16.

Neuman, W. Lawrence. 2007. Basics of Social Research. Qualitative and Quantitative Approaches. 2nd ed. Pearson Education, Inc.

Norris, Joe. 2000. 'Drama as Research: Realizing the Potential of Drama in Education as a Research Methodology'. Youth Theatre Journal 14 (1): 40-51. 
---. 2009. Playbuilding as Qualitative Research: A Participatory Arts-Based Approach. Walnut Creek, California: East Coast Press, Inc.

Opfermann, Lena S., 2015. Testing the "triple imperative": A drama-based exploration of migrant children's views. Transnational Social Review, 5(3), pp.224-240.

Opfermann, Lena S. (forthcoming): 'If you can't beat them, be them!' - Everyday Experiences and 'Performative Agency' among Undocumented Migrant Youth in South Africa, Children's Geographies.

Prentki, Tim, and Sheila Preston, eds. 2009. The Applied Theatre Reader. Routledge.

Saldaña, Johnny. 2005. 'Theatre of the Oppressed with Children: A Field Experiment'. Youth Theatre Journal 19 (1): 117-33.

Schneider, Rebecca. 2001. 'Performance Remains'. Performance Research 6 (2): 100-108.

Snyder-Young, Dani. 2011. 'Rehearsals for Revolution? Theatre of the Oppressed, Dominant Discourses, and Democratic Tensions'. Research in Drama Education: The Journal of Applied Theatre and Performance 16 (1): 29-45.

Thompson, James. 2002. 'Ugly, Unglamorous and Dirty: Theatre of Relief/Reconciliation/Liberation in Places of War'. Research in Drama Education: The Journal of Applied Theatre and Performance 7 (1): 108-14.

- - . 2009. Performance Affects: Applied Theatre and the End of Effect. Palgrave Macmillan. Vervliet, M., C. Rousseau, E. Broekaert, and I. Derluyn. 2015. 'Multilayered Ethics in Research Involving Unaccompanied Refugee Minors'. Journal of Refugee Studies. 